\title{
Survival in the Midst Of Challenges: Tale from ljora-Badia Slum Dwellers of Lagos State, Nigeria
}

\author{
Yussuf Lukeman1 \\ Bako, A.I ${ }^{2}$ \\ Omole, F.K ${ }^{3 *}$ \\ Nwokoro, I.I.C4 \\ 1,4Department of Urban and Regional Planning, University of Lagos \\ ${ }^{2}$ Department of Urban and Regional Planning, University of Ilorin \\ ${ }^{3}$ Department of Urban and Regional Planning, the Federal University of Technology, P.M.B 704Akure, Nigeria \\ Email: fkyomole@yahoo.co.uk
}

\section{Doi:10.5901/jesr.2014.v4n3p131}

\section{Abstract}

The history of slum development can be traced back to the era of industrial revolution and urbanization which was characterized by migration of people from rural areas to urban centres seeking a better means of livelihood because of the desire and anticipated opportunities at the urban centres. In this paper, the environmental health condition of slum dwellers in ljora-badia was examined. Some of the environmental health conditions data were collected via questionnaires, direct observation, personal interview, and focus group discussion. Some of the environmental health variables considered were major disease vector found, major disease suffered in the last one year health facilities patronized among others The research population was based on the total number of existing buildings from which the total numbers of household head were determined and 5\% of the total household head population was taken for the interview. The total numbers of 189 questionnaires were administered and responses were taken. Findings reveal that mosquitoes accounted for $77.8 \%$ of major disease vector found in various homes which is vector for malaria disease; malaria is the most prevalent environmental health disease which the respondents suffered in the last one year. The paper concludes that the healthcare facilities should be provided and located within the localities for easy accessibility of the people. In this wise, the federal, state and local governments 'Primary Health Care Delivery Programme' should be extended to the area and made affordable for the people.

Keywords: Slum dwellers, environmental health, household, Lagos, Nigeria.

\section{Introduction}

Environment and health are inextricably interlinked. Poor environment amenities such as unkempt drinking water, poor sanitation, poor housing, and polluted air, have considerable effects on the health status and well being of people, have contributed to communicable diseases, and prolong the epidemiological transition. The socio-cultural environment, such as changing lifestyles, modernization, occupational differentiation, and aspirations to improve the quality of life, not only results in new health problems but also places new demands on health systems. These socio-cultural and physical environmental factors cumulatively lead to a greater burden of disease. In the medical sense, the environment includes the surroundings, conditions or influences that affect an organism. Along these lines, Last, (2001) defined the environment for the International Epidemiological Association as: "All that which is external to the human host. This can be divided into physical, biological, social, cultural, etc., any or all of which can influence health status of populations". According to this definition, the environment would include anything that is not genetic, although it could be argued that even genes are influenced by the environment in the short or long-term.

In many parts of the developing world, the environmental health burden is increasing; even in the developed world, new pollutants are emerging which pose new threat to human health. The rate of urbanization in the developing world is on alarming rate. According to (UN Report, 2011) Nigeria projected population for year 2011 is 167 million which has resulted in the shortage of housing demand in the urban area. This has encouraged the new migrant or less privileged to develop their places of abode haphazardly resulting in slum development. Against this background, there is clearly an 
urgent need for action to reduce the environmental health burden, in some of the slum areas in the country. The slum development is common in developing nations which has caused a lot of problems that are being witnessed in various urban centres where the rate at which the infrastructure facilities are being provided lags seriously behind the rate of population growth and city expansion. The most vulnerable groups to environmental health burden in urban centre are the slum dwellers (Ezzati et-al, 2004). Similarly, the recent outbreak of cholera that was witnessed in Nigeria was peculiar to unhygienic environment and unplanned neighborhood or district all over the country especially in Lagos state. The cholera outbreak was very rampant in recent times and is peculiar to most of unplanned area in which ljora-Badia (the study area) is inclusive. In 2008, Minna the state capital of Niger state reported 230 cases and 17 deaths of outbreak of cholera (WHO, 2008). In September, 2011, Ibadan the state capital of Oyo, State, Nigeria 945 cases of cholera was recorded and 11 deaths were reported (The Nation, 2011). Again in July, 2011 in Makoko area in Lagos State, 10 cases were reported but no death was recorded (WHO, 2008, 2011). In 2008, eighty-four (84) cases of cholera were reported in the study area (ljora-badia) and seven (7) deaths were recorded (WHO, 2008). In view of the aforementioned, this study focuses on the environmental health conditions of slum dwellers in ljora-Badia ,Lagos, Nigeria.

\section{The Study Area}

ljora- Badia is one of the blighted area identified by UNDP which was also validated by the consulting firm SNC-Lavalin employed by Lagos State Government in the World Bank Assisted Infrastructure Upgrading programme for metropolitan Lagos (UNDP,1997).

Lagos is regarded as a mega city, because its population is estimated to be about 18 million people, with a population density of 20,000 persons/sq km (Mabogunje, 2002). Lagos state is on a built-up land area of about 18,558 Hectares made up of about 9,669 hectares (52.1\%). residential, commercial, 1,021 hectares (5.5\%); industrial, 1,448 hectares (7.8\%); institutional and special areas, 2,784 hectares (14\%); transportation 3,340 hectares (18\%), and open spaces 52 hectares (2.8\%). The Lagos metropolis comprises of $88.7 \%$ of Lagos State (Lagos State Economic Summit (2001).

The Lagos Metropolitan area with an area of 3557 square kilometers is defined as the continuous built-up area of Lagos, starting from the Atlantic Ocean in the south and spreading eastwards, westwards, and northwards. It includes eighteen of the twenty Local Government Areas of Lagos State and, another, four Local Government Areas of Ogun State. The vast territory of the Mega City is identified as covering 10 kilometers beyond the Lagos-Ogun State boundaries into Ogun State. The UN estimates that at its present growth rate, Lagos State will be the third largest mega city in the world by Year 2015 after Tokyo in Japan and Bombay in India. The rate of population growth is about 600,000 per annum with a population density of about 4,193 persons per sq. $\mathrm{km}$. In the built-up areas of Metropolitan Lagos, the average density is over 20,000 persons per square km (National Population Commission (NPC, 2006).

The study is set in the Lagos Metropolis, South Western Nigeria. Lagos Metropolis is situated within latitudes $6^{0}$ $23^{\prime} \mathrm{N}$ and $6^{\circ} 41^{\prime} \mathrm{N}$ and longitudes $2^{\circ} 42^{\prime} \mathrm{E}$ and $3^{\circ} 42^{\prime} \mathrm{E}$. It comprises settlements that have grown from predominantly farming and fishing villages to highly urbanized settlements. Lagos Metropolis is bounded in the west by Ojo and ljanikin, Lekki Peninsula in the east and Ikorodu and Alagbado towns in the north. The specific location of the study area is ljoraBadia one of the suburbs in the Apapa Local Government of Lagos State and it is located in the Southern fringe of the Lagos Metropolitan area. It is situated at the interaction point of the geographical latitude $3^{\circ} 23^{\prime}$ and longitude $4^{\circ} 22^{\prime}$. It is bounded in the North by the Lagos Badagry expressway link bridge into the National Theatre. A railroad to Apapa forms the Eastern boundary. The South is bounded by Ajegunle another low-income residential suburb.

\section{Literature Review}

Studies have shown that diarrhea, lower respiratory infections, malaria and other unintentional injuries are the diseases with the largest environmental contribution. Prüss-Üstün and Corvalán, (2006) estimated that 24 percent of the global disease burden and 23 percent of all deaths can be attributed to environmental factors, which can be prevented through environmental modification (such as through provision of safe water, improved sanitation, and adequate hygiene). The World Health Organization (WHO), The United Nations Children's Fund (UNICEF), and many other agencies have comprehensively shown that tackling environmental health issues is important. Environmental risk factors play a role in more than $80 \%$ of the major diseases and injuries worldwide. Developing countries carry disproportionately high environmental burden of disease, with the total number of healthy life years lost per capital as a result of environmental burden being 15-times higher in developing countries than in developed countries (Smith et al. 1999). Available global 
evidence suggests that (a) lack of access to clean water and sanitation and (b) indoor air pollution are the two principal risk factors of illness and death, mainly affecting children and women in poor families. The impact of such environmental health risks on men and women is substantial when measured in millions of deaths and disability adjusted life years (DALYs). This underscores the need to design and implement environmental health interventions in poor countries to improve access to safe water, provide adequate sanitation, and improve air quality, both indoors and outdoors. With 1.1 billion people lacking access to safe drinking water, and 2.6 billion without adequate sanitation, the magnitude of the water and sanitation problem remains significant (WHO/ UNICEF 2005). Each year contaminated water and poor sanitation contribute toward the 5.4 billion cases of diarrhea worldwide and the 1.6 million deaths, mostly among children under the age of five (Hutton and Haller 2004). Intestinal worms which thrive in poor sanitary conditions and in the poorest communities of the developing world have infected 2 billion people and, depending upon the severity of the infection, may lead to malnutrition, anemia or retarded growth, and subsequently diminished school performance (Ivanov et al. 2004). About 6 million people are blind from trachoma, a disease caused by the lack of water combined with poor hygiene practices. A further 200 million people are infected with schistosomiasis; of these, 20 million suffer severe consequences (UNICEF 2006). The most affected are the populations in developing countries living in extreme conditions of poverty, either in urban slums or peri-urban or rural areas. Indoor air pollution a much less publicized source of poor health is responsible for over 1.5 million deaths from respiratory infection per year and for 2.7 percent of the global burden of disease (WHO 2006). In developing countries, indoor air pollution is largely attributed to smoking and the use of biomass for cooking. It is estimated that half of the world's population use solid fuels (biomass and coal) for household cooking and space heating, mainly in developing countries (Rehfuess, et al. 2006). The burden of poor environmental health falls on the most vulnerable of the poor, mainly children under the age of five, women, and the disabled and elderly. As many as half of the deaths were attributable to indoor use of solid fuel and children under the age of five years paid dearly for this (Smith, et al. 2000). In the 21 worst affected countries, most of them located in subSaharan Africa, approximately 5 percent or more of the total burden of disease is caused by indoor air pollution. In 11 countries, Afghanistan, Angola, Bangladesh, Burkina Faso, China, the Democratic Republic of the Congo, Ethiopia, India, Nigeria, Pakistan, and the United Republic of Tanzania indoor air pollution is responsible for a total of 1.2 million deaths a year (WHO 2007). Generally, men suffer more from outdoor air pollution. Women are exposed more to indoor air pollution, since they traditionally spend more time indoors and near the stove. By far the greatest burden of disease falls on children under the age of five (Smith et al. 2000); they are especially susceptible to environmental risks when both risk factors are considered (Ezzati et al. 2004). In humans, malaria is a disease caused by one of four parasite species belonging to the genus Plasmodium. The parasite is transmitted by the bite of an infected female mosquito of the genus Anopheles. The larval stages of Anopheles mosquitoes occur in a wide range of habitats, but most species share a preference for clean, unpolluted, stagnant or slowly moving fresh water (Muir, 1988).

\subsection{Environmental health in Nigeria}

Analysis of current environmental health issues in the Nigeria presents a picture peculiar to developing countries is in "double jeopardy", suffering from 'traditional' primary environmental health problems associated with poverty and under-development as well as 'modern' secondary environmental health problem associated with unprecedented pace of industrialization and urbanization, which has brought about massive exploitation of natural resources and environmental degradation (Nigeria Demographic and Health Survey-NDHS, 2003). The primary environmental health problems include lack of sanitation and basic hygiene, unsafe water supply, inadequate waste disposal, poor food sanitation, as well as poor pest and vector control. According to the 2003 Nigeria Demographic and Health Survey (NDHS), 10.1\% of the urban population has no toilet facilities of any kind whilst $61.1 \%$ use pit latrines and $28.7 \%$ use flush toilets. The survey indicates that $34.1 \%$ of rural households have no toilet facilities at all. With regards to water supply facilities, the same survey show that $65 \%$ of the urban population have access to safe sources of drinking water, while about $70 \%$ of the rural population depend mainly on unsafe sources such as open wells, rivers streams etc. for drinking.

The secondary environmental health problems include exposure to hazardous chemicals, industrial pollution, noise pollution, climate change and stratospheric ozone depletion. Mention must be made here of the case of oil pollution from spillages in the crude oil production process. Other environmental challenges include erosion in the south east and desert encroachment from the north. The National Policy on Environment explicitly recognizes the importance of environment in the promotion of sound public health. The major thrust of the policy is to secure a quality of environment adequate for good health and well being. The recently developed National Environmental Sanitation Policy (2004) also has a major thrust of ensuring sound environmental sanitation practices that will promote sustainable development, 
public health and good quality of life. The policy document identifies the strategies, legislative provisions, institutional and funding arrangements needed for sound and sustainable environmental sanitation. In furtherance of the objectives of the policy, a National Action Plan has been developed to operationalize and translate all the components of the policy into time bound and measurable actions. Several legislative/regulatory instruments are in place to ensure environmental health and protection. These include:

i. Federal Environmental Protection Agency (FEPA) Decree No 58 of 1988 and No. 59 of

ii. 1992 as amended;

iii. National Environmental Protection (Effluent Limitations) Regulations S.18 of 1991 - mandatory for industries to install anti-pollution equipment and effluent treatment;

iv. National Environmental Protection (Pollution Abatement Indus tries and Facilities Generating Wastes ) Regulations S.19 of 1991;

v. National Environmental Protection (Management of Solid and Hazardous Wastes) Regulations S.1.15 of 1991;

vi. Environmental Impact Assessment (EIA) Decree No 86 of 1992;

vii. Guidelines on Hazardous Chemical Management 2001;

viii. $\quad$ Guidelines on Pesticides 2001;

ix. $\quad$ Blueprint on Municipal Solid Waste Management in Nigeria 2001;

x. The Blueprint on Handbook on Waste Management 2001;

xi. $\quad$ The Blueprint on Environmental Enforcement 2001;

In addition to the above, programmes in line with International Conventions and Protocols are in place for effective management of hazardous chemicals from 'cradle' to 'grave'. A lot of socio-behavioural characteristics have begun to adversely affect the life styles of the population. Mention should be made of the use of tobacco and sedentary life due to urbanization. This has increased the incidence of Non-communicable diseases such as cancers, coronary heart diseases etc. In Nigeria, about $52 \%$ of less than five years old deaths are associated with malnutrition. The problem of Malnutrition has been associated with poverty, which is the basic reason for lack of food. The major consequences of food insecurity are protein energy malnutrition and micronutrient deficiencies. A 1997 study conducted by Nigeria Demographic and Health Survey (NDHS), showed that only $26.6 \%$ of under-five children met their recommended dietary allowances or energy, while $8.5 \%$ were mildly deficient, $46.5 \%$ moderately deficient and $18.5 \%$ severely deficient. There are three micronutrient deficiencies, which are of pubic health importance, namely vitamin $A$, iron and iodine. Available data shows that prevalence of vitamin ' $A$ ' deficiency in 1993 was $9.2 \%$ in children and $7.2 \%$ in mothers and an estimated 25 million to 35 million Nigerians at risk of iodine deficiency.

The National Agency for Food and Drug Administration and Control (NAFDAC) is championing the safety of Food through appropriate registration of products, factory compliance, inspection and other administrative procedures for wholesomeness of food products in general, for human consumption. Of particular interest is the issue of fake and adulterated drugs which the agency is determined to eradicate. Through support from WHO, the Nutrition Division, has developed two training manuals. One for street food vendors and the other for Health officers involves in food inspection on safe handling practices for street food in Nigeria. This is part of the efforts geared towards food safety with large avenue for street vended food. In 1994 only 3,171 cases of cholera in various states in the federation were received with Case Fatality Rate (CFR) of 471 which translate to $14.85 \%$, one of the highest in the world. The prevalent of malnutrition is indicated by measurement of (weight/age) underweight is put at $29 \%$ for under five. Stunting (height/age) and wasting (weight/height) put at $33.7 \%$ and $9.3 \%$ respectively. Nutrition Information Surveillance System in the LGAs of each state where protein-energy malnutrition (PEM) data can be reasonably generated. The trends of low birth weight have deteriorated tremendously from $16 \%$ in 1999 to $33.7 \%$ in 2003. Micro nutrient deficiencies in under five as regard vitamin A, lodine, Iron and Zinc are 23\%, 27.5\%,34\% and 21\%. For mother, the deficiencies rates for vitamin A, Iron and Zinc are $13 \%, 25 \%$, and $24 \%$ and $28 \%$ respectively, and for pregnant women $19 \%, 33.8 \%, 40 \%$, and $43.7 \%$. All these clearly show different stages and condition of environmental health states in Nigeria.

\section{Methodology}

In order to capture significant data on environmental health conditions of slum dwellers in ljora-Badia, Lagos, Nigeria both primary and secondary sources of information were employed. These were obtained from the field through the use of research instrument such as administration of questionnaires, personal interviews, observations and focus group discussion. Secondary information were collected from reports, (published and unpublished sources), textbooks, journals, file of government agencies and parastatals. This was including the National Population Commission, The local 
government, and Internet among many others.

There are 539 residential buildings in ljora-Badia, Lagos (Tenament Rate Department Apapa Local Government, 2011). It has an average of minimum 7 households in a building, being a high residential area of metropolitan Lagos, which is in accordance with the National Population Commission (NPC) information of 2006. Since, the minimum average households per building is 7 households, the targeted population household in the study area translate to (539 $\mathrm{x}$ 7) three thousand seven hundred and seventy three $(3,773)$ households. The targeted household population of this study is 3,773 and the sample size is $5 \%$ of the targeted household population which translate to one hundred and eighty nine (189) and this becomes the total number of questionnaires administered for the study. In each district in the study area, $5 \%$ sample size were considered reasonable for this study because of the homogeneous characteristics that was peculiar to the residents in the study area.

The research adopts multi-stage sampling technique in the research procedure. First stage is the delineation and dividing ljora-Badia into three districts namely ljora-Badia West, ljora-Badia central, and ljora-Badia East (Onyeche, 2011).

Second stage is the identification of the buildings in each of the district by systematic sampling technique. All buildings in each district were arranged serially, from which the sampled buildings were selected. The $3^{\text {rd }}$ building forms the nth term while every $3^{\text {rd }}$ building was sampled from each district.

A randomly sampling technique was adopted in the third stage for the selection of household head sampled. This sampling method was based on household size in selected residential building. Household with highest number of people was selected

Finally, in each of the districts, questionnaires were administered systematically and randomly selection of household head on every $3^{\text {rd }}$ buildings in each district. The questionnaires were administered according to the number of buildings in the study area, as presented in table 1.

Table 1: Distribution of questionnaires in the study area (ljora-Badia).

\begin{tabular}{|l|l|c|}
\hline Name of districts & Number of Buildings in each District & Number of Questionnaires Administered \\
\hline ljora-badia West & 129 buildings & 45 \\
\hline ljora-badia Central & 230 buildings & 81 \\
\hline ljora-badia East & 180 buildings & 63 \\
\hline Total & 539 Buildings & 189 \\
\hline
\end{tabular}

Source: Tenament rate department Apapa Local Government (2012).

\section{Research Findings}

Major findings of this study are discussed below

\subsection{The diseases vectors found in the study area}

The diseases vectors found in different homes have direct effect on the disease that likely attack by the residents in the study area. $77.8 \%$ of disease vector found is mosquitoes, $3.2 \%$ of the disease vector found was bedbug and $19.0 \%$ of the disease vector found was cockroach. The highest disease vector found in the study area was mosquitoes which was major diseases vector for malaria, see table 2 .

Table 2: Major Disease Vector found in houses

\begin{tabular}{|l|c|c|}
\hline Disease Vectors & Frequency & Percentages \\
\hline Mosquitoes & 147 & 77.8 \\
Bedbug & 6 & 3.2 \\
Cockroach & 36 & 19.0 \\
Total & 189 & 100.0 \\
\hline
\end{tabular}

Source: Authors' Field Survey, 2012

\subsection{The major disease suffered in the area.}

Table 3 shows that, $3.7 \%$ of respondents suffered from cholera disease, $85.2 \%$ of respondents suffered from malaria disease, $9.5 \%$ of respondents suffered from typhoid fever, $1.1 \%$ of respondents suffered from dysentery and $0.5 \%$ of 
respondent suffered from tuberculosis. It was deduced that malaria was the most prevalent environmental disease in the study area.

Table 3: Major Disease suffered in the last one year

\begin{tabular}{|l|c|c|}
\hline Major Diseases & Frequency & Percentages \\
\hline Cholera & 7 & 3.7 \\
Malaria & 161 & 85.2 \\
Typhoid & 18 & 9.5 \\
Dysentery & 2 & 1.1 \\
Tuberculosis & 1 & .5 \\
Total & 189 & 100.0 \\
\hline
\end{tabular}

Source: Authors' Field Survey, 2012

\subsection{The number of times respondents suffered from various diseases in the study area.}

The number of times respondents suffered from various diseases in the study area in the last one year shows that, $31.7 \%$ of respondents suffered once in last one year, $43.4 \%$ of respondents suffered twice in last one year, $15.9 \%$ of respondents suffered three times in last one year, $5.3 \%$ of respondents suffered five times in last one year and $3.7 \%$ of respondents suffered more than six times in the last one year (Table 4). It is deduced that every respondents in the study area was attacked by various diseases.

Table 4: Number of times suffered from the disease in the last one year

\begin{tabular}{|l|c|c|}
\hline Number of Times & Frequency & Percentages \\
\hline Once & 60 & 31.7 \\
Twice & 82 & 43.4 \\
Three times & 30 & 15.9 \\
Five times & 10 & 5.3 \\
More than six times & 7 & 3.7 \\
Total & 189 & 100.0 \\
\hline
\end{tabular}

Source: Authors' Field Survey, 2012

\subsection{Disease attributed to slum condition}

The respondents attributed some diseases to poor slum conditions in the study area which shows that, $12.2 \%$ of respondents attributed the poor slum condition to outbreak of cholera, $2.1 \%$ of respondents admitted that diarhorrea was as a result of poor slum condition, $70.9 \%$ of respondents attributed the poor slum conditions to malaria disease, $10.6 \%$ of respondents belief that typhoid fever is as a result of poor slum condition, $3.7 \%$ of respondents opined that dysentery is as a result of poor slum living condition and $0.5 \%$ of the respondent attributed the poor slum living condition to tuberculosis. It can be deduced from table5 that malaria fever been experienced in the study area as most prevalent environmental disease is as a result of poor slum living condition.

Table 5: Major disease attributed to poor slum condition

\begin{tabular}{|l|c|c|}
\hline Major Diseases & Frequency & Percentages \\
\hline Cholera & 23 & 12.2 \\
Diarhorrea & 4 & 2.1 \\
Malaria & 134 & 70.9 \\
Typhoid & 20 & 10.6 \\
Dysentery & 7 & 3.7 \\
Tuberculosis & 1 & .5 \\
Total & 189 & 100.0 \\
\hline
\end{tabular}

Source: Authors' Field Survey, 2012 


\subsection{Types of Health facilities patronized in the study area}

The health facilities patronized by the residents in the study area indicate the high level of illegal private clinic own and manage by the quack nurses. It has shown that $27 \%$ of respondents' patronized general hospital in Apapa, $35.4 \%$ of respondents patronized unregistered private clinic, $12.7 \%$ of respondents' patronized chemist, $21.2 \%$ of respondents patronized the traditional medicine and $3.7 \%$ of respondents depends on self medication. It was concluded that majority of respondents' patronized unregistered private clinic which is very dangerous to health care services of the residents in the study area. Despite, the fact that, general hospital is the most reliable health care facility, the residents prefer to patronize unregistered private clinic.

Table 6: Health facilities patronized by the dwellers

\begin{tabular}{|l|c|c|}
\hline Health Facilities & Frequency & Percentages \\
\hline General hospital & 51 & 27.0 \\
Private clinic & 67 & 35.4 \\
Chemist & 24 & 12.7 \\
Traditional medicine & 40 & 21.2 \\
Self medication & 7 & 3.7 \\
Total & 189 & 100.0 \\
\hline
\end{tabular}

Source: Authors' Field Survey, 2012

\subsection{Distance travelled to Health facilities.}

The distance of health facility to various houses in the study area show $47.1 \%$ of respondents considered their health facility distance less than 100 meters, $29.1 \%$ of respondents considered their health facility distance between $200 \mathrm{~m}$ $500 \mathrm{~m}, 22.2 \%$ of respondents considered their health facility distance to be between $501 \mathrm{~m}-1 \mathrm{~km}$ and $1.6 \%$ of respondents considered their health facility distance to be between $101 \mathrm{~km}-3 \mathrm{~km}$. It is deduced that the distance of health facility is not far from their various home and those private clinic were own and manage by the quack doctors.

Table 7: Distance of health facilities

\begin{tabular}{|l|c|c|}
\hline Distance to Health Facilities & Frequency & Percentages \\
\hline Less than $100 \mathrm{~m}$ & 89 & 47.1 \\
$200 \mathrm{~m}-500 \mathrm{~m}$ & 55 & 29.1 \\
$501 \mathrm{~m}-1 \mathrm{~km}$ & 42 & 22.2 \\
$101 \mathrm{~km}-3 \mathrm{~km}$ & 3 & 1.6 \\
Total & 189 & 100.0 \\
\hline
\end{tabular}

Source: Authors' Field Survey, 2012

\section{Recommendations and Policy Guidelines}

The major recommendation and policy guidelines of this study are presented below

- The healthcare facilities should be provided and located within the localities for easy accessibility of the people. In this wise, Federal, state and local governments Primary Health Care Delivery Programme should be extended to the area and make affordable for the people.

- Countries need to recognize that the urban poor are active agents and not just beneficiaries of development. Local authorities and national governments should collaborate with the organizations of the urban poor in upgrading slums and providing alternatives to slum formation such as provision of site and services.

- Local governments should develop strategies to prevent the formation of new slums. These should include access to affordable land, reasonably priced materials, employment opportunities, and basic infrastructure and social services.

- Public investments must focus on providing access to basic services and infrastructure. Working with the 
urban poor, cities need to invest in housing, water, sanitation, energy, and urban services, such as garbage disposal. These services and infrastructure must reach the poor living in informal settlements.

- Finally, while a total clearance of the slum in the study areas may not be feasible because of the cost elements, inconvenience and other logistic problems it might cause. It is evidence from the study that the level of deterioration is still redeemable. Programme like Urban Basic Service (UBS) which encompasses provision of facilities, environmental campaign will not only reduce the environmental health risks of slum dwellers but will also usher in a functional, liveable and aesthetically pleasing environment.

\section{References}

Ezzati M, Rodgers A, Lopez AD, Hoorn SV and Murray C (2004): Mortality and Burden of Disease Attributable to Individual Risk Factors. In eds. Comparative Quantification of Health Risks: Global and Regional Burden of Disease Attributable to Selected Major Risk Factors. Geneva: World Health Organization. Retrieved from http//www.who.org on 13/05/2011 at 1.15am

Hutton, G and Haller, L (2004): Evaluation of the Costs and benefits of Water and Sanitation Improvements at the Global Level. Geneva: World Health Organization. Available at: http://www.who.int/water_sanitation_health/wsh0404/en/index.html on 13/05/2011 at $1.15 \mathrm{am}$

Ivanov, ID Licari, L and Bertollini, R eds. (2004): Health and the environment in the WHO European Region: Situation and policy at the beginning of the 21st century. Fourth Ministerial Conference on Environment and Health, Budapest, June 23-25, 2004. WHO Regional Office for Europe. Available at http://www.euro.who.int/document/eehc/ on 13/05/2011 at 1.20am

Last, JM (2001): A dictionary of epidemiology, 4th ed. New York, Oxford University Press, International Epidemiological Association. Retrieved on http//www.oxford university.com on 13/07/2011 at 9.05am

Mabogunje, A.L (2002): 2002 National Housing and Urban Development Policy: Catalyst for Mass Housing Delivery in Nigeria; Lead Paper Presented at the Second Abuja International Housing Summit Held at the Le Meridien Hotel Abuja.

Muir, D.A (1988): Anopheline mosquitoes: vector reproduction, life cycle and biotope. In: Wernsdorfer WH, McGregor I., eds. Malaria. Principles and practices of malariology. New York, Churchill Livingstone .Rerrieved from http//www.who.org on 05/07/2011 at 9.45am

National Demographic and Health Survey (NDHS) (2003): Retrieved from http//www.nigeriahealthreport.com on 17/05/2011 at 1.00am.

National Population Commission (2006): Census Report in Nigeria

Onyeche, .E (2011): Ijora Badia: Slum for decades" Unpublished Article Retrieved from http//www.slumnigeria.org on 17/6/2011

Rehfuess EA, Mehta S and Prüss-Uestün A (2006): Assessing household solid fuel use: multiple implications for the Millennium Development Goals. Environmental Health Perspectives 114: 373-378.

Smith KR, Corvalàn FC and Kjellström T (1999): How much ill Health is Attributable to Environmental Factors? Epidemiology, 10(5):573-584.Retrieved from http//www.environmental_ health.org on 17/07/2011 at 4.15pm

Smith KR, Samet JM, Romieu I and Bruce N (2000): Indoor air pollution in developing countries and acute lower respiratory infections in children. Thorax, 55(6):518-532.Retrieved from http//www.environmental_health.org on 17/07/2011 at 4.25pm

SNC Lavalin Report in Agbola, T \& Agunbiade, M. (2007): Urbanization, Slum Dēvelopment and Security of Tenure: The Challenges of Meeting Millenium Development Goal (MDG) 7 in Metropolitan Lagos. Paper Presented to The PRIPODE Workshop on Urban Population, Development and Environment Dynamics in Developing Countries Jointly organized by CICRED, PERN and CIESIN With Support From The APHRC, Nairobi, Kenya.

Tenament Rate Department, (2011): Apapa Local Government Apapa Lagos State.

The Nation News Paper (2011): Vol 7 No 1888 pg 3-5

UNDP, (1997): Human Development Report to Eradicate Poverty. Retrieved from http://www.unhabitat.org on 13/04/2011 at 12.00pm

UNICEF, (1999): website: http://www.unicef.org.Retrieved on 04/7/2011 at 2.15am

UNICEF,(2006): UNICEF Statistics: Water. Assessed from http //www.ChildInfo.org on 17/07/2011 at 4.45pm

UN-HABITAT, (2011): Population Report in Developing Countries. Retrieved from http//www.unhabitat.org on 04/07/2011 at 12.05pm

WHO/UNICEF (2005): Water for Life: Making it Happen. Joint Monitoring Programme Report. Available at: http://www.wssinfo.org/en 140_wfl_2005.html on 19/07/2011 at 1.05am

WHO (2006): Fuel for life: household energy and health. Geneva: World Health Organization. Assessed from http//www.who.org on $22 / 07 / 2011$ at $12.30 \mathrm{am}$

WHO (2007): Indoor air pollution: National burden of disease estimates. Geneva: World Health Organization. Assessed from $\mathrm{http//www.who.org} \mathrm{on} \mathrm{22/07/2011} \mathrm{at} \mathrm{12.30am}$

WHO, (2008): Cholera Report in Nigeria. Retrieved from http//www.who.org. on 13/05/2011 at 1.05am. 